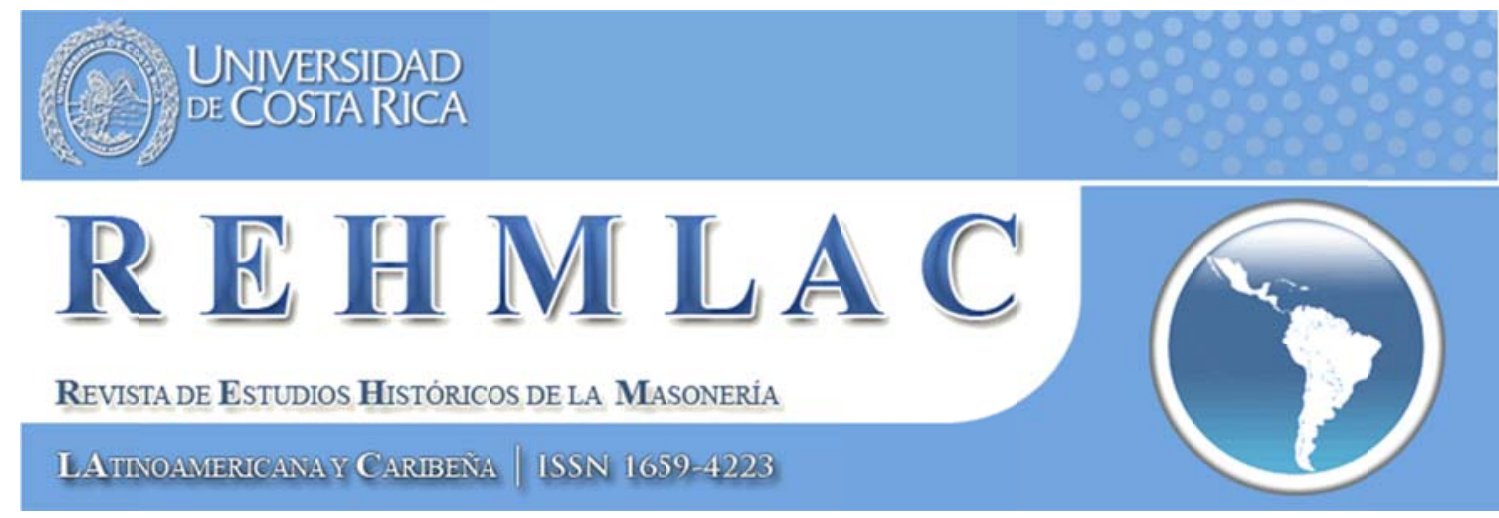

Delphine Sappez

“Ciudadanía y autonomismo en Cuba en el siglo XIX: el compromiso de Antonio Govín y Torres (1847-1914)”

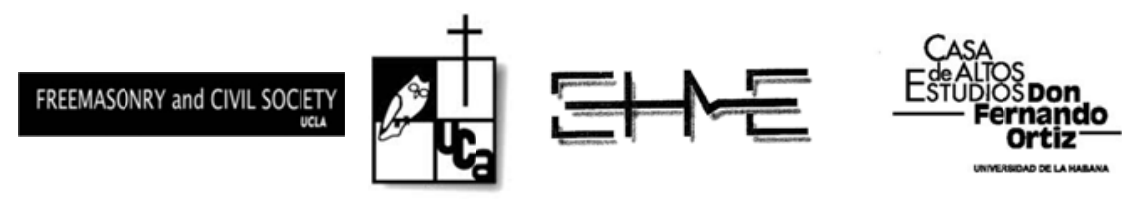


(C) Delphine Sappez y REHMLAC.

\section{Equipo REHMLAC}

Consejo Científico:

Miguel Guzmán-Stein (Universidad de Costa Rica, Costa Rica)

José Antonio Ferrer Benimeli (Universidad de Zaragoza, España)

Margaret Jacob (University of California Los Angeles, United States)

Eduardo Torres Cuevas (Universidad de La Habana, Cuba)

María Eugenia Vázquez Semadeni (Stanford University, United States)

Éric Saunier (Université du Havre, France)

Andreas Önnerfors (Lunds universitet, Sverige)

Samuel Sánchez Gálvez (Universidad Carlos Rafael Rodríguez de Cienfuegos, Cuba)

Roberto Valdés Valle (Universidad Centroamericana “José Simeón Cañas”, El Salvador)

Céline Sala (Université de Perpignan, France)

Dominique Soucy (Université de Franche-Comté, France)

Guillermo de los Reyes Heredia (University of Houston, United States)

Dévrig Mollès (Université de Strasbourg, France)

Felipe Santiago del Solar Guajardo (Universidad ARCIS, Santiago de Chile)

Carlos Francisco Martínez Moreno (Universidad Nacional Autónoma de México, México)

Michel Goulart da Silva (Universidade do Estado de Santa Catarina, Brasil)

Correctores de estilo:

Sylvia Hottinger (Centro de Estudios Históricos de la Masonería Española, España)

Kyle Jackson (University of California Los Angeles, United States)

Diseñador y administrador Web:

Luis Martín Valverde Alfaro (Universidad de Costa Rica, Costa Rica)

Editor:

Yván Pozuelo Andrés (IES Universidad Laboral de Gijón, España)

Correo electrónico: yvan@edu.xunta.es

Director:

Ricardo Martínez Esquivel (Universidad de Costa Rica, Costa Rica)

Correo electrónico: ricardo.martinezesquivel@ucr.ac.cr

Dirección Web: rehmlac.com/

Correo electrónico: info@,rehmlac.com

Apartado postal: 243-2300 San José, Costa Rica 
Citado en:

Academia.edu

Aladin. WRLC. Libraries Catalog

AFEHC. Asociación para el Fomento de los Estudios Históricos en Centroamérica Biblioteca de Georgetown

CRICCAL, Université Sorbonne Nouvelle Paris 3

CERGE EI. Portál elektronických časopisů. Univerzita Karlova v Praze

Departamento de Filosofía de la Universidad Centroamericana "José Simeón Cañas"

Dialnet, Universidad de la Rioja

Directorio y recolector de recursos digitales del Ministerio de Cultura de España

DOAJ. Directory of Open Access Journals

Freemasonry and Civil Society Program at UCLA

Fudan University Library Academic Resource Portal

Google académico

Institute for the Study of the Americas at University of London

Latindex (UNAM)

Latindex.ucr. Repositorio de revistas de la Universidad de Costa Rica

Library Catalogue of University of South Australia

Museo Virtual de la Historia de la Masonería de La UNED

Nuevo Mundo. Mundos Nuevos

REDIAL. Red Europea de Información y Documentación sobre América Latina SciELO

SID. Sistema Integrado de Documentación. Universidad Nacional de Cuyo

Toronto Public Library

UBO. Revues en ligne. Université de Bretagne Occidentale

Universia. Biblioteca de Recursos

University of Wiscosin-Madison Libraries

Western Theological Seminary. Beardslee Library Journals 


\title{
“Ciudadanía y autonomismo en Cuba en el siglo XIX: el compromiso de Antonio Govín y Torres (1847-1914)”
}

\author{
Delphine Sappez \\ Doctora en Historia por la Universitat Jaume I de Castelló, España (2013). \\ Correo electrónico: delphine@his.uji.es
}

La investigadora Delphine Sappez ha defendido una Tesis Doctoral, cuyo título es "Ciudadanía y autonomismo en Cuba en el siglo XIX: el compromiso de Antonio Govín y Torres (1847-1914)” en la Universitat Jaume I de Castelló, el 22 de noviembre de 2013.

Delphine Sappez nació en el 6 de julio de 1986 en Saint-Claude, Francia.

La autora nos ha concedido la siguiente entrevista.

\section{¿Cuáles fueron los motivos que le llevaron a enfocar su investigación hacia la masonería?}

Mi tesis doctoral, titulada Ciudadanía y autonomismo en Cuba en el siglo XIX: el compromiso de Antonio Govín y Torres (1847-1914), es una biografía política, social y cultural de un jurista, masón y político cubano, olvidado a pesar de su protagonismo en la esfera pública cubana de las últimas décadas del siglo XIX. Su papel central en la masonería cubana de la época, en la que desempeñó la función de gran maestro desde 1877 hasta 1891, y sobre todo la importancia que él mismo concedió a la institución en su proyecto de renovación de la sociedad cubana, me llevaron a interrogarme acerca del verdadero papel que cumplió su actividad masónica en su trayectoria pública y el alcance real de su esfuerzo por convertir a la masonería en el motor de la creación de una sociedad armónica en Cuba.

En realidad, el interés por este personaje se originó en un estudio sobre la masonería cubana, la tesis doctoral de la profesora Dominique Soucy, publicada en el año 2006 con el título Masonería y nación. Redes masónicas y políticas en la construcción identitaria cubana (1811-1902) (ediciones Idea). Analiza las conexiones entre la masonería y los movimientos políticos a través de una ideología compartida que la autora nombra "pensamiento masónicoliberal". En este sentido, Antonio Govín aparecía como un nexo fundamental entre masonería y política. Ella me propuso el tema de investigación.

Bajo la dirección del profesor José Antonio Piqueras, lo que había empezado como un análisis de discurso se convirtió en una biografía completa del personaje, en la que he procurado mostrar la complejidad de una trayectoria marcada por el proceso de intenso cambio que conoció Cuba en las últimas décadas del siglo XIX y las primeras del siglo XX, particularmente entre 1868 y 1909. Mi interés por el proceso de formación del pensamiento de Antonio Govín hasta su plasmación en la doctrina autonomista que elaboró en torno al año 1880 me llevó a revisitar no sólo la historia política escrita sobre la isla hasta la fecha, sino también la historia de las ideas y, por supuesto, la historia masónica cubana. 
En esta reconstrucción de los pasos de Antonio Govín hacia la secretaría del Partido Liberal Autonomista, su iniciación masónica en el año 1874 se presentó rápidamente, en efecto, como un hito fundamental, en el que pueden verse muchos de los tópicos que se vinculan a este acontecimiento en la vida de un hombre en cuanto rito de paso a la edad adulta: Govín entró en la institución a los 27 años, recién acabados sus estudios, en el mismo año en que se casó y poco antes de establecer su propio bufete de abogado. Era el candidato perfecto para una organización como la masonería cubana que ya prefería -aunque todavía se encontrara en proceso de definición- a hombres mayores de 25 años, de intachable moralidad y con una situación profesional estable para no convertirse en cargas para la institución.

Además, se hizo masón en un momento peculiar en que la situación de guerra con la metrópoli había traído consigo desde 1868 la prohibición de todo tipo de asociación y la persecución contra los masones. En consecuencia, el Gran Oriente de Colón, hasta entonces radicado en Santiago de Cuba, se encontraba en una situación un tanto irregular y complicada a raíz del traslado temporal de los poderes de la Gran Logia a La Habana. Antonio Govín se vio entonces inmerso en una batalla masónica en la que, más allá de las disputas de poder entre masones habaneros y santiagueros, lo que estaba en juego eran las distintas concepciones de la identidad cubana. Al ser la masonería la única asociación a su alcance, los hombres que como Antonio Govín tenían el afán de comprometerse con el destino social, económico y político de la isla hicieron de la institución masónica el medio de expresar sus ideas acerca del futuro de Cuba. De ahí que, en un año tan incierto como 1876, la masonería cubana se dividiera en tres obediencias que pocos años después se reunieron cuando la aparición de los partidos políticos y de una relativa libertad de prensa permitió que las diferencias políticas se expresaran a través de otros canales. No obstante, el análisis profundizado de estas batallas masónicas de finales de la década de 1870, silenciadas por una historiografía masónica preocupada por demostrar su unidad, se hacía necesario para comprender lo que realmente estaba en juego en ellas, puesto que constituyeron un claro precedente a la creación de los partidos políticos en 1878 .

Para la década siguiente, época de pleno apogeo de Antonio Govín como personaje público, también he otorgado en la redacción un lugar destacado a la masonería, de nuevo como espacio en el que se manifestaban ciertos conflictos que no podían aparecer a la luz del día, excluidos del debate político: en particular, el conflicto de poder entre cubanos y peninsulares. Desde finales de los años 1870 y con cada vez más intensidad en los 1880 , se organizaron en la isla logias dependientes de las distintas obediencias españolas que rechazaban todas -excepto la Gran Logia Independiente Española radicada en Sevilla- la legitimidad de la masonería cubana sobre un territorio que consideraban de su jurisdicción por ser una colonia. En sus vehementes ataques contra la "invasión" de Cuba por una masonería extranjera en contra de toda regla masónica, Antonio Govín hacía uso de un vocabulario que a menudo puede entenderse en un sentido equívoco y trasladarse al mundo profano. Lo que estaba en juego, para él, era el derecho de los cubanos a tomar las riendas de su futuro, aunque no cuestionara el mantenimiento del vínculo colonial con España, que sin embargo no debería traducirse sino en un papel de mera supervisión. 
Por otro lado, la evolución de la masonería cubana en los años 1880, incluso después de su unificación en 1881, también refleja con una fidelidad asombrosa las alianzas o divisiones políticas entre las distintas fracciones liberales. De este modo, el fracaso de los intentos de acercamiento entre logias de obediencia cubana y española en la primera mitad de los años 1880, en el que las resistencias de Antonio Govín desempeñaron un papel decisivo, refleja la política autonomista de aquellos años, de rechazo a cualquier intento de negociación y a cualquier reducción de su programa; es un momento de afirmación de la élite intelectual cubana en que el objetivo principal, tanto en el ámbito político como científico, cultural o masónico, consistía en demostrar su capacidad para pensar y actuar de manera independiente de la metrópoli. En cambio, a principios de los años 1890, la prioridad dada por la mayoría de los miembros del Partido Autonomista a los intereses económicos de la isla se tradujo en el abandono de hecho de la reivindicación de la autonomía y la colusión con el sector peninsular favorable a las reformas económicas. Fue entonces cuando Antonio Govín abandonó su puesto de gran maestro para dejar paso a un peninsular que representara mejor los intereses políticos del momento.

La masonería está, por tanto, omnipresente en la tesis, pero en filigrana: el protagonismo de Antonio Govín tanto en la esfera masónica como política y científica, a través de su compromiso con el adelanto de la ciencia jurídica cubana, pone en evidencia no sólo los puntos de encuentro entre estas distintas esferas, sino la amplitud de sus zonas de contacto y la atribución de un objetivo común a cada una de ellas por unos dirigentes también compartidos: la transformación de la sociedad cubana en una sociedad liberal y capitalista. El análisis conjunto de estas distintas esferas a través del prisma que representa Antonio Govín también nos proporciona los medios de realizar una radiografía más completa de la sociedad cubana del momento y de sus mecanismos internos.

\section{¿Cuáles fueron las fuentes que utilizó?}

Además de algunos documentos relacionados con la masonería cubana y periódicos masónicos procedentes del Archivo Histórico Nacional de Salamanca y de los fondos del Gran Oriente de Francia, facilitados amablemente por la Dra. Soucy, la mayor parte de las fuentes consultadas pertenecen a la biblioteca y al archivo de la Gran Logia de Cuba, donde se conservan importantes colecciones de prensa masónica de finales del siglo XIX, aunque incompletas. En la Biblioteca Nacional José Martí de La Habana también tuve acceso a publicaciones periódicas del mismo período y a algunos de los reglamentos y constituciones de las distintas obediencias existentes en Cuba en los años 1870 y 1880. El profesor cienfueguero Samuel Sánchez Gálvez me facilitó la consulta de otros volúmenes de prensa que me permitieron completar un amplio abanico temporal gracias al cual pude reconstruir en detalle la historia de la masonería cubana en las décadas de 1870, 1880 y 1890 y observar sus estrechos vínculos con la esfera pública a través de sus protagonistas.

En el archivo de la Gran Logia de Cuba, donde se conservan los papeles de muchas logias habaneras, pude consultar los de la logia Amor Fraternal, logia más antigua de La Habana en la que se inició Antonio Govín en 1874 y que también fue la logia donde se 
desencadenó el conflicto entre los masones habaneros que condujo a la creación en 1876 de la Gran Logia de la Isla de Cuba en La Habana y al traslado de la Gran Logia de Colón a la misma ciudad en 1877, bajo la dirección de Govín, mientras algunos masones santiagueros se resistían y mantenían otra Gran Logia de Colón en la capital oriental.

\section{¿Cuáles fueron las principales dificultades con las que se ha encontrado? ¿Cómo las ha superado?}

El mal estado de ciertas fuentes, el frecuente cierre de las bibliotecas cubanas por obras u otros motivos, y sobre todo la dificultad para localizar las fuentes dificultaron mi trabajo. La mejor arma para superar este tipo de problemas es, además de los siempre imprescindibles contactos, el tiempo y la paciencia: una primera estancia de nueve meses (2007-2008), en la que fui acogida por el Dr. Eduardo Torres-Cuevas, y otra posterior de dos meses (2011) fueron necesarias para localizar y recopilar el amplio corpus de prensa con el que he trabajado, en el que sin embargo quedan algunos períodos vacíos, y finalmente vencer las resistencias de los masones habaneros a franquearme el paso hacia su archivo. En el año 2011 tuve además la alegría de poder visitar la logia Antonio Govín, creada en 1944 en Casablanca, al otro lado de la bahía de La Habana, gracias a la confianza de William Rojas, gran secretario de la Gran Logia de Cuba, y de Yunier Espinosa, segundo vigilante de dicha logia.

\section{¿Cuáles fueron las principales problemáticas históricas que su trabajo ha resuelto?}

Partiendo de la hipótesis según la cual el proyecto autonomista constituía un proyecto global para la sociedad cubana y respondía a la pretensión de elaborar una solución ideal a los principales problemas que suponían las necesidades de transformación política, económica y social para adaptar el país a las exigencias del mundo "civilizado" contemporáneo, cuyas instancias más representativas serían el Estado liberal y el capitalismo, la principal problemática que ha guiado mi investigación se atenía a la medida en que este proyecto podía verse como una vía de realización de la soberanía cubana, es decir, a si realmente convertiría a los cubanos en ciudadanos de una nación propia, aunque no correspondiera a un Estado independiente.

El análisis del pensamiento de Antonio Govín conjuntamente con su trayectoria, la cual arroja luz sobre muchos silencios de su discurso, permite entender su ideal de autonomía colonial como un atrevido proyecto de "colonia-nación", como medio más viable de acceder a la soberanía política sin caer en el caos en que a su entender habían caído las repúblicas hispanoamericanas u otras islas antillanas como Haití, evitando al mismo tiempo el riesgo de perder la identidad cultural cubana asociado a la eventualidad de la anexión a Estados Unidos. Pero sin duda alguna, la principal función de la limitación de la soberanía cubana que suponía el mantenimiento de la relación colonial con España tenía que ver con la permanencia de la posibilidad, como una espada de Dámocles, de la intervención del ejército metropolitano para restablecer el orden en el caso de que las clases más bajas de la sociedad -en las que se concentraba la mayoría de la población negra- no se encontraran satisfechas con la limitada 
participación que la clase media a la que Antonio Govín pertenecía y representaba estaba dispuesta a concederles. Govín confiaba en que las iniciativas lanzadas principalmente desde la masonería para "educar y dirigir" a las clases subalternas serían suficientes para mantenerlas controladas pero la conservación de una válvula de seguridad como la que representaba España constituía una considerable ventaja, al menos hasta que aquella labor de educación quedara terminada. Ahora bien, omitía un detalle importante: el hecho de que esta solución solamente podría funcionar en el caso de que España aceptara convertirse en una metrópoli "moderna" y renunciara a usar su poder para oprimir a la colonia.

Este estudio también pone de relieve el fracaso de la opción autonomista originado precisamente en la falta de realismo que suponía aquella confianza, en la que se reconoce la influencia krausista recibida por Antonio Govín, en la posibilidad de crear una sociedad desigual pero armónica en la que las clases más desfavorecidas pudieran abandonar toda voluntad propia y aceptar la dirección y orientación de una clase media con intereses opuestos a los suyos. Los autonomistas no fueron capaces de incluir a esas clases en su proyecto dándoles un protagonismo real, mientras que en la guerra de 1895 y antes con la creación del Partido Revolucionario Cubano en 1892 los líderes independentistas supieron desarrollar un discurso mucho más atractivo para obreros y campesinos basado en el ideal democrático de la República para todos de José Martí.

\section{¿Por favor, podría resumir la esencia de su Tesis en dos líneas?}

¡No! Digamos que mi tesis reconstruye la trayectoria de un patriota cubano en la difícil encrucijada que suponía la necesidad de entrar en un mundo moderno para una sociedad esclavista y dominada por un gobierno arbitrario. En el contexto de la creación de las naciones, la autonomía colonial de Antonio Govín respondía al osado desafío de hacer de Cuba una nación moderna salvando aquellos lastres de la sociedad colonial sin poner en peligro el orden necesario para no ralentizar la marcha del "progreso". Un ideal tan burgués como cubano que no ha tenido su lugar en la historiografía oficial de la isla.

\section{¿Cuáles fueron las lecciones, a todos los niveles, personal y profesional, que usted ha deducido de su experiencia doctoral?}

Dedicar tantos años (siete, en mi caso) al estudio de un tema en particular, y además muy específico, como suele pasar con las tesis doctorales, lleva a menudo al investigador a identificarse con su tema, tal vez con mayor facilidad aún si este tema es una persona. El día en que llegué al final del último capítulo de mi tesis y tuve que escribir la muerte de Antonio Govín -de hecho, lo hice de una forma muy abrupta, queriendo salir del trance cuanto antesmurió también una parte de mí, una parte que yo misma había obligado a desarrollarse considerablemente a lo largo de esos años puesto que fue la que realizó el sostenido esfuerzo necesario para transformar las investigaciones realizadas en una larga tesis. No creo equivocarme afirmando que muchos doctorandos habrán experimentado esa sensación de vacío al escribir el punto final de su tesis, preguntándose si realmente conseguirían empezar 
una nueva vida en la que el tema quedara ausente, abrumados por el deseo contradictorio de olvidarlo para siempre y el miedo a quedarse sin motivación vital. Tal vez por ello resulte que muchos investigadores nunca abandonen del todo su tema de tesis doctoral, por mucho que se alejen de él sus posteriores investigaciones.

Sin embargo, este vacío se compensa ampliamente por todo lo aprendido a lo largo del camino de la investigación. Sin duda alguna, las enseñanzas más ricas, tanto a nivel personal como profesional, nacen de los encuentros que se producen más o menos casualmente al hilo de los pasos que se dan, más o menos al azar, en busca de información. Con mi director de tesis, el Dr. Piqueras, y el grupo de Historia Social Comparada de la Universitat Jaume I de Castellón he aprendido a interrogar las fuentes y a no darme nunca por satisfecha con explicaciones medianamente convincentes, lo que me ha llevado a visitar numerosos archivos cubanos, españoles y estadounidenses en busca de un amplio corpus de fuentes que me permitiera proponer las interpretaciones más justas posibles. En cada uno de los lugares a los que me ha conducido mi tema he conocido a archiveros e investigadores dispuestos a enseñarme los mecanismos y los secretos destinados a facilitar mi búsqueda: gracias a ellos he aprendido a adaptarme a diferentes condiciones de trabajo y a aprovechar al máximo el tiempo de que disponía en cada archivo. En las distintas actividades académicas en las que he participado, siempre gracias al interés y al apoyo de numerosos investigadores, he aprendido a exponer mis ideas, defenderlas y reconsiderarlas en función de las reacciones que han suscitado.

Todas las personas a las que debo esas enseñanzas tenían un rasgo común: su pasión por la historia. Al estar en contacto con ellas la mía ha crecido y se ha convertido en un oficio: podría decirse que de aprendiz he llegado al grado de compañera.

\section{¿Ahora, cuáles son sus proyectos profesionales?}

Me gustaría poder proseguir mi formación como investigadora mediante un contrato postdoctoral, dentro o fuera de España, y el desarrollo de una nueva investigación, que tal vez me lleve a interesarme por la masonería puertorriqueña. De momento estoy preparando una versión reducida de mi tesis con el objetivo de publicarla.

\section{¿Quisiera destacar algún aspecto que no se ha contemplado y que usted consideraría digno de reseñar?}

Quiero manifestar mi agradecimiento al equipo redactor de REHMLAC, que me dio la oportunidad de publicar mi primer texto (en coautoría con Dominique Soucy) en el año 2009, por su interés y confianza en mi trabajo.

Esta entrevista se efectuó de forma telemática el 23 de febrero de 2014.

Autores de la entrevista: Ricardo Martínez Esquivel e Yván Pozuelo Andrés, Director y Editor de REHMLAC. 